
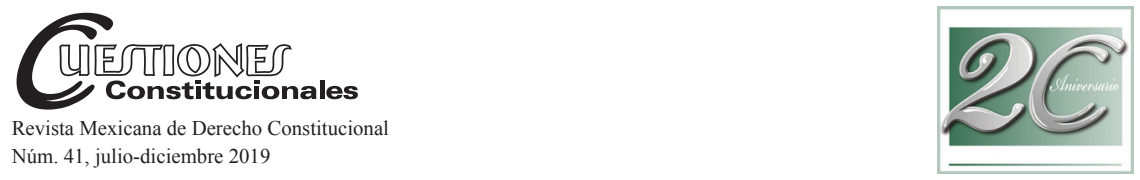

\title{
El plazo de interposición de la acción de inconstitucionalidad y los derechos humanos
}

\author{
The term of interposition of the action of unconstitutionality \\ and human rights
}

\author{
Alberto HERRERA PÉREZ* \\ Eduardo Alberto HERRERA MONTES** \\ edfra semper iunctus
}

\begin{abstract}
RESUMEN: El plazo establecido en la Ley Reglamentaria de las Fracciones I y II del Artículo 105 de la Constitución Política de los Estados Unidos Mexicanos para interponer la acción de inconstitucionalidad, en el caso de normas generales lesivas de derechos humanos, debe adecuarse $o$, en definitiva, ser intemporal.
\end{abstract}

Palabras clave: Derechos humanos, plazos procesales, normas generales, acción de inconstitucionalidad.
ABSTRACT: The term established in the Regulatory Law of Fractions I and II of the Article 105 of the Political Constitution of the United States of Mexico to interpose the abstract action of unconstitutionality, in the case of general norms detrimental to human rights, must be adequate or be timeless.

Keywords: Human rights, procedural deadlines, general rules, unconstitutionality action.

* Especialista en derecho penal por la Universidad Panamericana, México; especialista en derecho constitucional por la UNAM; maestro en derecho por la Universidad Marista;edfra5@hotmail.com.

** Estudiante de la Licenciatura en Derecho en la Universidad Tecnológica de México, campus sur, México. 


\begin{abstract}
SUMARIO: I. Exordio. II. Delimitación analítica. III. La acción de inconstitucionalidad como medio de impugnación a violaciones de los derechos humanos. IV. Instrumentos jurídicos internacionales. V. Corolario. VI. Conclusiones. VII. Fuentes consultadas.
\end{abstract}

\title{
I. EXORDIO
}

Los derechos humanos corresponden al ser humano por el solo hecho de revestirse de tal calidad que le confiere una racionalidad, la cual demanda el respeto a su dignidad, ${ }^{1}$ permitiéndole un desarrollo armónico en la sociedad. $^{2}$

La alta importancia de estos derechos llevada al texto de nuestra ley fundamental, en la reforma a la Constitución Política de los Estados Unidos Mexicanos (CPEUM) del 10 de junio de 2011, no deja margen de discusión para comprender una obligada preeminencia en su defensa y tutela.

La reforma constitucional del artículo 105 constitucional, del 31 de diciembre de 1994, transformó el papel del Poder Judicial de la Federación, al otorgarle a la Suprema Corte de Justicia de la Nación la facultad de conocer las acciones de inconstitucionalidad.

La génesis de este medio de control surge con la finalidad de otorgar a las minorías parlamentarias la posibilidad de impugnar ante los organismos de justicia constitucional las disposiciones legislativas aprobadas por la mayoría; es un control abstracto de la Constitución respecto de actos formal y materialmente legislativos (leyes) ${ }^{3}$ cuyas disposiciones son contrarias a los principios o postulados de la Constitución federal.

\section{DELIMITACIÓN ANALÍTICA}

En la Ley Reglamentaria de las Fracciones I y II del Artículo 105 de la Constitución Política de los Estados Unidos Mexicanos (Ley o la Ley),

1 Herrera Pérez, Alberto, "La dignidad humana en la Constitución federal mexicana", Revista de la Facultad de Derecho de México, México, t. LXVI, julio-diciembre de 2016, p. 126.

2 Herrera Pérez, Alberto, "Correlación jerárquica normativa de los tratados internacionales en materia de derechos humanos y la Constitución federal mexicana", Revista El Tribunal Superior de Justicia del Distrito Federal, núm. 22, año VIII, diciembre de 2015, p. 146.

3 Sin olvidar los tratados internacionales. 
se prevé un plazo único in genere para la interposición de los medios de control constitucional (controversia constitucional y acción de inconstitucionalidad), sin considerar la materia de impugnación (fiscal, electoral, administrativa, etcétera).

A partir de la reforma constitucional de junio de 2011, se faculta a la Comisión Nacional de los Derechos Humanos y a otros organismos defensores de los derechos humanos para impugnar normas generales (vía acción de inconstitucionalidad) ${ }^{4}$ donde se reclame la invalidez de actos lesivos (normas generales) a los derechos humanos.

El presente ensayo se encaminará a establecer si el ejercicio de una acción de inconstitucionalidad interpuesta en contra de un acto del Poder Legislativo o de un tratado internacional, presumiblemente lesivos o invasivos de los derechos humanos, debe reglarse bajo los mismos supuestos o plazos procesales establecidos para las demás materias, o si es necesario conferirle un régimen procesal especial, bajo la óptica de que su interposición debe guardar un especial tratamiento atendiendo a la naturaleza axiológica de estos derechos.

Específicamente analizaremos si el plazo para interponer la acción abstracta de inconstitucionalidad, previsto en la Ley Reglamentaria de las Fracciones I y II del Artículo 105 de la Constitución Política de los Estados Unidos Mexicanos, debe permanecer en su actual redacción o es necesaria su modificación o adecuación para lograr alcanzar un espectro tutelar más amplio en la defensa de los derechos humanos.

\section{LA ACCIÓN DE INCONSTITUCIONALIDAD COMO MEDIO}

DE IMPUGNACIÓN A VIOLACIONES DE LOS DERECHOS HUMANOS

Por defensa de la Constitución se puede entender el conjunto de instrumentos procesales cuyo objetivo es hacer valer el contenido, los alcances y la evolución de la ley constitucional. ${ }^{5}$

Constituyen medios de control constitucional, el juicio de amparo, la controversia constitucional, la acción de inconstitucionalidad, los proce-

4 Muy posiblemente la controversia constitucional podría constituirse como un medio eficaz de combatir actos lesivos a los derechos humanos; sin embargo, este análisis escapa a los fines de este ensayo.

5 Suprema Corte de Justicia de la Nación, Grandes temas del constitucionalismo mexicano, la defensa de la Constitución, México, 2005, p. 16. 
sos jurisdiccionales en materia electoral, los medios de protección de los derechos humanos y el juicio político.

La acción de inconstitucionalidad se define como un medio de control abstracto de constitucionalidad cuyo objeto es llevar a cabo "...un control de la regularidad constitucional, en términos de lo dispuesto en la parte inicial de la fracción II del artículo 105 de la Constitución, ya que siempre se contrastará una norma legal o un tratado internacional contra la propia Constitución". ${ }^{6}$

Armando Guadalupe Soto Flores ${ }^{7}$ sostiene que la acción de inconstitucionalidad es:

...el modo de control de la constitución - por lo mismo garantía constitucional- en virtud del cual ciertos sujetos legitimados por el texto constitucional pueden instar el control abstracto de una norma general ante la Suprema Corte de Justicia de la Nación, a efecto de que ésta pueda determinar si existe una contradicción entre dicha norma y la Constitución Federal o los tratados internacionales en que el Estado mexicano sea parte.

\section{Por su parte, Brage Camazano afirma:}

...aquel mecanismo o instrumento procesal-constitucional por medio del cual determinadas personas, órganos o fracciones de órganos, cumpliendo los requisitos procesales legalmente establecidos (siempre que sean conformes con la Constitución), pueden plantear, de forma directa y principal, ante el órgano judicial de la constitucionalidad de que se trate, si una determinada norma jurídica (y especialmente, las leyes parlamentarias) es o no conforme con la Constitución. ${ }^{8}$

La referencia a "control abstracto" significa que el análisis o estudio se lleva a cabo completamente al margen de todo caso concreto y de la aplicación que haya podido tener la ley cuestionada, la que en ocasiones aún

6 Cossío, José Ramón y Acha Pérez, Luis M. de, La defensa de la Constitución, México, Distribuciones Fontamara, 2003, p. 67.

7 Soto Flores, Armando Guadalupe, La controversia constitucional y la acción de constitucionalidad como medios de control de la Constitución, México, UNAM, Instituto de Investigaciones Jurídicas, 2017, p. 164 [en línea, 9 de enero de 2019], disponible en: https://archivos.juridicas.unam.mx/www/bjv/libros/9/4456/8a.pdf.

8 Brage Camazano, Joaquín, La acción abstracta de inconstitucionalidad, México, UNAM, 2000, p. 2. 
no se ha aplicado ni generado agravio alguno; por lo tanto, no se requiere la afectación de un interés legítimo; basta con la promoción por parte de los órganos o entes públicos especificados para la procedencia de esta vía.

El aspecto fundamental de esta acción abstracta es afirmar y tutelar el principio de supremacía constitucional (en virtud del cual toda norma debe ajustarse a los lineamientos establecidos en la carta magna) otorgando certeza y congruencia al orden jurídico. Es precisamente esta característica hegemónica la que otorga orden y coherencia a la estructura normativa del Estado mexicano, ya que no es posible entender la vigencia de normas generales contrarias a las disposiciones, principios y valores insertos en la ley fundamental.

En la originaria reforma constitucional por la que se crea la acción de inconstitucionalidad (DOF del 31 de diciembre de 1994), los sujetos procesales legitimados para interponerla se constituían por el equivalente al treinta y tres por ciento de la Cámara de Diputados del Congreso de la Unión; el equivalente al treinta y tres por ciento de los integrantes de la Cámara de Senadores; el procurador general de la República; el equivalente al treinta y tres por ciento de los integrantes de los órganos legislativos estatales, y el equivalente al treinta y tres por ciento de los integrantes de la Asamblea de Representantes; en esa reforma constitucional se estableció el plazo para interponer la acción de inconstitucionalidad de treinta días naturales siguientes a la fecha de publicación de la norma. Un detalle significativo es la excepción que se hace para ejercer esta acción respecto de leyes electorales.

Posteriormente (DOF del 22 de agosto de 1996), se agregarían como sujetos legitimados a los partidos políticos, y las leyes electorales como materia de la acción de inconstitucionalidad.

Una reforma importante a nuestra ley fundamental en materia de sujetos procesales legitimados para interponer la acción de inconstitucionalidad se produce al adicionarse a su artículo 105, fracción II, un inciso que correspondería a la letra $g$ ), en el cual se otorga la facultad de interponer este tipo de acciones a la Comisión Nacional de los Derechos Humanos en contra de leyes de carácter federal, estatal y del Distrito Federal, así como de tratados internacionales celebrados por el Ejecutivo Federal y aprobados por el Senado de la República que vulneren los derechos humanos consagrados en la Constitución y en los tratados internacionales de los que México sea parte. Asimismo, los organismos de protección de los derechos humanos equivalentes en los estados de la República, en contra de leyes expedidas por las legislaturas locales, y la Comisión de Derechos Humanos del Dis- 
trito Federal en contra de leyes emitidas por la Asamblea Legislativa del Distrito Federal (DOF del 10 de junio de 2011). ${ }^{9}$

Parece inferirse (atendiendo al contenido de esta última reforma constitucional) que antes del otorgamiento a las comisiones defensoras de derechos humanos de la facultad de combatir leyes: "que vulneren los derechos humanos consagrados en esta Constitución y en los tratados internacionales de los que México sea parte", la acción de inconstitucionalidad no se erigía como un medio procesal constitucional directo (como el juicio de amparo) para impugnar violaciones a los derechos humanos por leyes o tratados internacionales.

Las materias objeto de la impugnación en estas acciones se referían fundamentalmente a cuestiones electorales, fiscales, administrativas, civiles, etcétera.

Las materias electoral y fiscal concentran la mayor parte de las acciones de inconstitucionalidad, aunque la diferencia porcentual entre una y otra es muy alta. Por lo que respecta a la materia administrativa, los temas más recurridos se relacionan con la rama municipal, la asistencia social, los servicios y la creación de órganos administrativos. Resulta interesante observar que casi el $50 \%$ de las acciones en materia administrativa se refieren a la creación de órganos, institutos y organismos descentralizados a nivel estatal, y que el principal motivo de controversia tiene que ver con el régimen laboral de dichas instituciones...

Lo anterior demuestra que los temas relacionados con el poder político y con el poder económico son los que más interesan a los órganos legitimados. En un segundo plano se encuentran los temas relacionados con libertades y derechos, integración y facultades de los órganos electorales y distritación. Esto significa que los partidos políticos se preocupan no sólo por las reformas jurídicas que inciden en su ámbito político o económico, sino que además siguen de cerca las reformas que versan sobre el órgano electoral que los regula y buscan impactar naturalmente tanto en su integración como en sus facultades...

9 España fue el primer país donde se legitimó al Ombudsman para interponer el recurso de inconstitucionalidad, y su ejemplo ha sido seguido por varios países europeos y latinoamericanos que han instaurado un tribunal constitucional y un defensor del pueblo, atribuyéndole a este funcionario la legitimación para impugnar directamente la constitucionalidad de las leyes. Es el caso, por ejemplo, de Polonia o Ucrania en el viejo continente, y en América tenemos como ejemplos la Constitución guatemalteca de 1985, la peruana de 1993, la boliviana de 1994, la ecuatoriana de 1995 o la venezolana de 1999. Brage Camazano, Joaquín, op. cit., p. 172. 
La materia electoral es por mucho la más controvertida, particularmente, por los partidos políticos..., ahora bien, resulta interesante observar cuáles son los artículos constitucionales más utilizados en las acciones de inconstitucionalidad. El análisis realizado muestra que son los siguientes: $14,16,116,41$ y $133 \ldots$

Por otro lado, se observa que a menudo se argumenta la vulneración de los artículos 14 y 16 constitucionales como una especie de muletilla en relación con otros artículos impugnados, o bien, para demandar aspectos formales del procedimiento, violaciones a los principios de legalidad, seguridad jurídica y el debido proceso. Es decir, los promoventes invocan la violación de dichos preceptos para "reforzar" sus planteamientos; no obstante, tal como se verá ulteriormente, en pocas ocasiones la Corte ha determinado que efectivamente existen transgresiones a estos artículos. Una situación similar se da con el artículo 133, en cuyo caso se argumenta lateralmente que se violenta el principio de supremacía constitucional. ${ }^{10}$

De acuerdo con el estudio anterior, parece desprenderse que en las acciones de inconstitucionalidad analizadas no existía o no se argumentaba como concepto de invalidez la violación directa a los derechos humanos por parte de una ley emanada del Congreso de la Unión o tratado internacional.

En otras palabras, este medio de control se reservó, en sus orígenes, para combatir normas legislativas donde la materia de impugnación o motivos de invalidez no se refería a violaciones directas a derechos humanos, sino a otras diversas (electoral, ${ }^{11}$ fiscal, administrativa, etcétera); en estos casos, al no relacionarse las materias de impugnación de manera directa con el tema de los derechos humanos, el plazo constitucional (treinta días naturales) ${ }^{12}$ para su interposición podría no resultar inadecuado; sin embargo, para el momento en que esta acción se erige como medio de impugnación de nor-

10 López-Ayllón, Sergio y Valladares, Florencio, "Las acciones de inconstitucionalidad mexicana: balance empírico de doce años de ejercicio", Cuestiones Constitucionales, Revista Mexicana de Derecho Constitucional, México, núm. 21, julio-diciembre de 2009, pp. 188-192.

11 Entendemos que la materia electoral tutela igualmente derechos humanos.

12 El artículo 60 de la Ley Reglamentaria de las Fracciones I y II del Artículo 105 de la Constitución Política de los Estados Unidos Mexicanos establece:

"El plazo para ejercitar la acción de inconstitucionalidad será de treinta días naturales contados a partir del día siguiente a la fecha en que la ley o tratado internacional impugnado sean publicados en el correspondiente medio oficial. Si el último día del plazo fuese inhábil, la demanda podrá presentarse el primer día hábil siguiente.

En materia electoral, para el cómputo de los plazos, todos los días son hábiles”. 
mas generales lesivas directamente de estos derechos, debe obligadamente, para este plazo, mantenerse una especial consideración. ${ }^{13}$

Es interesante apuntar que dentro de los medios de control constitucional, y específicamente aquellos encaminados a la protección de los derechos humanos, como es el juicio de amparo, se establecen excepciones al plazo de interposición de la demanda, atendiendo precisamente a la naturaleza del acto reclamado y a su impacto en la violación de los derechos fundamentales.

La Ley de Amparo, en su artículo 17, fracciones II y IV, establece:

Artículo 17. El plazo para presentar la demanda de amparo es de quince días, salvo:

II. Cuando se reclame la sentencia definitiva condenatoria en un proceso penal, que imponga pena de prisión, podrá interponerse en un plazo de hasta ocho años;

IV. Cuando el acto reclamado implique peligro de privación de la vida, ataques a la libertad personal fuera de procedimiento, incomunicación, deportación o expulsión, proscripción o destierro, desaparición forzada de personas o alguno de los prohibidos por el artículo 22 de la Constitución Política de los Estados Unidos Mexicanos, así como la incorporación forzosa al Ejército, Armada o Fuerza Aérea nacionales, en que podrá presentarse en cualquier tiempo.

Observemos cómo en contra de actos presumiblemente violatorios de derechos humanos (debido proceso, libertad personal, vida, integridad personal, derecho al acceso a la justicia, derecho al reconocimiento a la personalidad jurídica, etcétera) existen plazos privilegiados para reclamar o combatir su posible inconstitucionalidad, atendiendo, precisamente, a su naturaleza axiológica.

En otras palabras, la Ley de Amparo, para aquellos actos de autoridad que impactan de una manera superior los principios y valores inherentes a

13 Respecto de las causales para sobreseer, desechar o desestimar las acciones de inconstitucionalidad, el estudio de López-Ayllón señala: "Como puede observarse la causal que con mayor frecuencia se presenta se refiere a la extemporaneidad. Esto lleva a preguntarse si el plazo establecido para la promoción es idóneo o si conviene ampliarlo para extender la posibilidad que los órganos legitimados interpongan una acción de inconstitucionalidad. Una segunda reflexión es que, con excepción de un caso, todas las acciones sobreseídas por esta causal corresponden a la materia electoral, la cual tiene un régimen distinto en su tramitación, se trata de plazos más cortos para la sustanciación y resolución del procedimiento, con la finalidad de tener certeza respecto de las leyes aplicables al proceso electoral del que se trate". López-Ayllón, op. cit., p. 199. 
los derechos humanos, privilegia los tiempos procesales de interposición de la demanda, extendiéndolos (ocho años) o estableciendo su inexistencia (en cualquier tiempo) de acuerdo con la naturaleza propia del acto reclamado.

De lo anterior se sigue que la tutela procesal o jurisdiccional de los derechos humanos debe obligadamente regirse bajo tiempos de privilegio.

Entendemos que la reglamentación relativa a las formalidades y plazos en los medios de defensa se dirigen a asegurar la buena administración de justicia y el respeto en particular del principio de seguridad jurídica; sin embargo, los requisitos procesales ( $v$. gr. el plazo de interposición) no deben restringir o hacer nugatorio el derecho humano tutelado hasta un punto que se encuentre afectado en su propia esencia; debe existir una relación razonable de proporcionalidad y congruencia entre las exigencias procesales y la finalidad perseguida, de ahí que los requisitos procesales en el caso de violaciones a los derechos humanos deben ser sometidos a un examen y consideración particularmente especiales. ${ }^{14}$

Los aspectos procesales relativos a los medios de control constitucional, en el tema relativo al combate de actos emanados de aparatos de poder presumiblemente violatorios de derechos humanos, deben revertir características de excepción, en razón a que las violaciones en esta materia no

14 Tesis: I.4o.A. J/1 (10a.), Semanario Judicial de la Federación y su Gaceta, Décima Época, Tribunales Colegiados de Circuito, libro XVI, enero de 2013, t. 3, p. 1695. “ACCESO A LA JUSTICIA. LOS ÓRGANOS JURISDICCIONALES DEBEN EVITAR, EN TODO MOMENTO, PRÁCTICAS QUE TIENDAN A DENEGAR O LIMITAR ESE DERECHO. A fin de satisfacer efectivamente el derecho fundamental de acceso a la justicia, debe acudirse al artículo 25 de la Convención Americana sobre Derechos Humanos, el cual prescribe la obligación por parte del Estado, de conceder a toda persona bajo su jurisdicción, un recurso judicial efectivo contra actos violatorios de derechos, los cuales pueden estar reconocidos tanto en la legislación interna, como en la propia convención. Asimismo, en la interpretación que se ha hecho de este numeral por parte de la Corte Interamericana de Derechos Humanos, ha sido criterio sostenido que, para la satisfacción de dicha prerrogativa, no basta con la existencia formal de un recurso, sino que éste debe ser efectivo; es decir, capaz de producir resultados o respuestas y tener plena eficacia restitutoria ante la violación de derechos alegada; en otras palabras, la obligación a cargo del Estado no se agota con la existencia legal de un recurso, pues éste debe ser idóneo para impugnar la violación y brindar la posibilidad real, no ilusoria, de interponer un recurso sencillo y rápido que permita alcanzar, en su caso, la protección judicial requerida. En estas condiciones, la existencia de esta garantía constituye uno de los pilares básicos, no sólo de la Convención Americana citada, sino de todo Estado de derecho. Por tanto, los órganos jurisdiccionales deben evitar, en todo momento, prácticas que tiendan a denegar o limitar el referido derecho de acceso a la justicia". 
trascienden ni alcanzan los mismos aspectos axiológicos que otras (fiscal, electoral, administrativa etcétera). ${ }^{15}$

Atentos a este razonamiento, para la acción de inconstitucionalidad debe existir un tratamiento distinto en el plazo de conocimiento por parte del tribunal constitucional en los casos de una posible violación a los derechos humanos, sin sujeción a rígidos límites temporales procesales que impidan su tutela judicial efectiva.

Ciertamente, la existencia de un debate entre el principio de seguridad jurídica de las normas generales ${ }^{16}$ y la permanencia de una violación de un derecho humano cuya impugnación se sujeta a rígidos plazos procesales es inevitable; sin embargo, consideramos que debe decantarse la decisión hacia el aspecto tutelar de los derechos humanos.

En el establecimiento de tiempos procesales para la interposición de un medio de control, en el caso de los derechos humanos, debe atenderse, por imperativo constitucional, a la observancia del principio pro homine, el cual ordena que las normas de derechos humanos deben interpretarse y

15 Tesis: I.3o.C. J/1 (10a.), Semanario Judicial de la Federación y su Gaceta, Décima Época, Tribunales Colegiados de Circuito, libro XV, diciembre de 2012, t. 2, p. 1189. "REQUISITOS PROCESALES BAJO LA ÓPTICA CONSTITUCIONAL DE LOS DERECHOS HUMANOS. Aunque doctrinal y jurisprudencialmente se afirmaba, con carácter general y sin discusión, la naturaleza de derecho público de las normas procesales, consideradas de cumplimiento irrenunciable y obligatorio, debe considerarse que con motivo de la reforma constitucional de junio de dos mil once, en la actualidad es en la finalidad de la norma, que tiene que mirarse en función del valor justicia, donde radica el carácter de derecho público de los requisitos procesales. Por ello, será competencia del legislador, de la jurisdicción ordinaria y de la jurisdicción constitucional, en su caso, velar porque los requisitos procesales sean los adecuados para la obtención de los fines que justifican su exigencia, para que no se fijen arbitrariamente y para que respondan a la naturaleza del proceso como el camino para obtener una tutela judicial con todas las garantías. Y si la ley no contempla expresamente esta flexibilidad, ello no será obstáculo para que el juzgador interprete y aplique la norma de una manera diversa a la prescrita, en aras de encontrar un equilibrio entre seguridad jurídica y justicia. De aquí se destaca la regla: flexibilizar lo procesal y privilegiar lo sustantivo".

16 Hans Kelsen, en su obra La garantía jurisdiccional de la Constitución (UNAM, Instituto de Investigaciones Jurídicas, 1974), señala: es también conveniente examinar si no sería bueno, en interés de la seguridad jurídica, que la anulación, en particular de las normas generales y principalmente de las leyes y tratados internacionales, no procedieran sino dentro de un plazo fijado por la Constitución, por ejemplo, de tres a cinco años, a partir del momento de la entrada en vigor de la norma irregular. Ya que sería extremadamente lamentable tener que anular una ley, o aún peor, un tratado por inconstitucionalidad después de que han estado en vigor durante largos años sin haber sido criticados (p. 504). 
aplicarse extensivamente en todo cuanto favorezca al ser humano y al pleno goce de estos derechos, y restrictivamente en todo lo que los excluya, restrinja, condicione o exceptúe (preferencia interpretativa), en tanto los conflictos de normas deben resolverse siempre en el sentido más favorable al ser humano (preferencia normativa).

Este principio no sólo debe ser observado en la interpretación o aplicación de normas generales, sino también en la labor legislativa al momento de manufacturarse una ley, atendiendo, además, entre otros principios, al de progresividad de los derechos humanos. ${ }^{17}$

Al mismo tiempo, esta doble positivación — del ser del derecho y de su deber ser jurídico- equivale a la completa realización y a la ampliación del Estado de derecho, pues el legislador deja de ser omnipotente y queda igualmente subordinado a la ley constitucional, no sólo en lo que atañe a las formas de la producción jurídica sino también en lo relativo a los contenidos normativos producidos. ${ }^{18}$

17 Tesis: 1a. CCXCI/2016 (10a.), Semanario Judicial de la Federación, Décima Época, Primera Sala, publicación: viernes 02 de diciembre de 2016 10:14 h. "PRINCIPIO DE PROGRESIVIDAD DE LOS DERECHOS HUMANOS. SU CONCEPTO Y EXIGENCIAS POSITIVAS Y NEGATIVAS. El principio de progresividad está previsto en el artículo 1o. constitucional y en diversos tratados internacionales ratificados por México. Dicho principio, en términos generales, ordena ampliar el alcance y la protección de los derechos humanos en la mayor medida posible hasta lograr su plena efectividad, de acuerdo con las circunstancias fácticas y jurídicas del caso concreto. Es posible diseccionar este principio en varias exigencias de carácter tanto positivo como negativo, dirigidas a los creadores de las normas jurídicas y a sus aplicadores, con independencia del carácter formal de las autoridades respectivas, ya sean legislativas, administrativas o judiciales. En sentido positivo, del principio de progresividad derivan para el legislador (sea formal o material) la obligación de ampliar el alcance y la tutela de los derechos humanos; y para el aplicador, el deber de interpretar las normas de manera que se amplíen, en lo posible jurídicamente, esos aspectos de los derechos. En sentido negativo, impone una prohibición de regresividad: el legislador tiene prohibido, en principio, emitir actos legislativos que limiten, restrinjan, eliminen o desconozcan el alcance y la tutela que en determinado momento ya se reconocía a los derechos humanos, y el aplicador tiene prohibido interpretar las normas sobre derechos humanos de manera regresiva, esto es, atribuyéndoles un sentido que implique desconocer la extensión de los derechos humanos y su nivel de tutela admitido previamente. En congruencia con este principio, el alcance y nivel de protección reconocidos a los derechos humanos tanto por la Constitución como por los tratados internacionales, deben ser concebidos como un mínimo que el Estado Mexicano tiene la obligación inmediata de respetar (no regresividad) y, a la vez, el punto de partida para su desarrollo gradual (deber positivo de progresar)".

18 Ferrajoli, Luigi, Garantísmo, una discusión sobre derecho y democracia, Madrid, Trotta, 2006, p. 28. 
La Suprema Corte de Justicia de la Nación, al dictar sobreseimiento por extemporaneidad, lo ha realizado bajo diversos argumentos, entre otros: cuando el acto legislativo impugnado no provoca un cambio sustancial o material, sino uno meramente formal al haberse reproducido el texto anterior (acción de inconstitucionalidad 87/2016); al no impugnarse en tiempo un nuevo acto legislativo (acción de inconstitucionalidad 55/2016). ${ }^{19}$ Asimismo, ha fijado criterio en el sentido de que la presentación de dicha acción debe realizarse bajo los estrictos términos de la LRF I y II 105. ${ }^{20}$

Respecto de consideraciones extensivas de la SCJN, en el caso de la existencia de modificaciones normativas materiales que pudieran permitir un nuevo plazo para impugnar una norma general (por ejemplo por constituir un nuevo acto legislativo), el criterio de este alto tribunal es en el sentido: a) que se haya llevado a cabo un proceso legislativo (criterio formal), y b) que la modificación normativa sea sustantiva o material; ${ }^{21}$ creemos que una reforma o adecuación normativa por parte del legislador únicamente habilita un nuevo plazo respecto de la porción normativa materia de la reforma, no así en relación con aspectos legales intocados por el legislador (aun en el caso de la existencia, en la norma general reformada, de derechos humanos violentados que no constituyeron materia de la modificación legal) y que en su oportunidad no fueron combatidos por

19 Fuente: https://sjf.scjn.gob.mx/sjfsist/Paginas/ResultadosV2.aspx?Epoca $=f \& E x p r$ esion $=$ extempor $\%$ C3\%Alnea $\% 20$ acci\%C3\%B3n\%20de\%20inconstitucionalidad\&Dom inio $=$ Temasintesis, Tema, Texto,Asunto \&TATJ $=0 \&$ Orden $=1 \& b c=$ Ejecutorias. $\% 20$ Result ados \&Clase $=$ EjecutoriasBL\&Osol $=3 \&$ Hits $=20 \&$ Octava $=1$.

20 Tesis: 2a. LXXIX/99, Semanario Judicial de la Federación y su Gaceta, Novena Época, Segunda Sala, t. IX, junio de 1999, p. 657. "ACCIÓN DE INCONSTITUCIONALIDAD. EL CÓMPUTO DEL PLAZO PARA LA PRESENTACIÓN DE LA DEMANDA DEBE REALIZARSE A PARTIR DEL DÍA SIGUIENTE DE LA PUBLICACIÓN DE LA DISPOSICIÓN GENERAL COMBATIDA. De conformidad con el artículo 60 de la Ley Reglamentaria de las Fracciones I y II del Artículo 105 de la Constitución Política de los Estados Unidos Mexicanos, el plazo para ejercitar la acción de inconstitucionalidad es de treinta días naturales a partir del día siguiente a la fecha en que la ley o tratado internacional impugnado sean publicados en el correspondiente medio oficial; por tanto, es a partir del día siguiente de la publicación oficial que debe realizarse el cómputo respectivo, con independencia de que, con anterioridad a esta fecha, la parte que ejerce la acción haya tenido conocimiento o se manifieste sabedora de la disposición impugnada".

21 Tesis: P./J. 25/2016 (10a.), Gaceta del Semanario Judicial de la Federación, Décima Época, Pleno, libro 35, octubre de 2016, t. I, p. 65. "Acción de inconstitucionalidad. Lineamientos mínimos requeridos para considerar que la nueva norma general impugnada constituye un nuevo acto legislativo". 
algún medio constitucional; por otra parte, para el caso de una nueva ley, es factible creer que se actualizan los plazos previstos para su impugnación.

Por lo demás, no advertimos de nuestro más alto tribunal ninguna consideración tutelar especial sobre la temporalidad en la presentación de esta acción más allá de lo previsto por la ley reglamentaria.

\section{INSTRUMENTOS JURÍDICOS INTERNACIONALES}

Demos una breve mirada a lo que disponen algunos cuerpos normativos iberoamericanos sobre el tema del plazo para interponer la acción de inconstitucionalidad y acciones similares de defensa de los derechos humanos.

\section{Perú}

El artículo 100 del Código Procesal Constitucional, Ley 28237, de la República de Perú, dispone que la demanda de inconstitucionalidad de una norma debe interponerse dentro del plazo de seis años contado a partir de su publicación, salvo el caso de los tratados, en que el plazo es de seis meses.

\section{Bolivia}

El artículo 202.1 de la Constitución del Estado Plurinacional de Bolivia y el Código Procesal Constitucional dejan abierta la posibilidad de que la acción de inconstitucionalidad abstracta pueda ser presentada en cualquier momento, en tanto la norma cuya constitucionalidad se cuestiona esté vigente.

\section{Colombia}

El artículo 242 de la Constitución Política de Colombia, en su punto 3, establece que las acciones de inconstitucionalidad, entre otras, caducan en el plazo de un año por vicios de forma. 


\section{Ecuador}

El artículo 78 de la Ley Orgánica de Garantías Jurisdiccionales y Control Constitucional establece que el plazo para interponer las acciones de inconstitucionalidad por razón de su contenido será en cualquier momento, mientras que por razones de forma pueden ser interpuestas dentro del año siguiente a su entrada en vigencia.

\section{Chile}

El artículo 93 de la Constitución Política de la República de Chile confiere dos plazos a este tipo de acciones dependiendo del órgano legitimado para impugnar; así, en el caso del presidente de la República, tendrá diez días; en el caso de cualquiera de las cámaras legislativas, el plazo será de treinta días, contados a partir de la publicación del decreto con fuerza de ley.

\section{Venezuela}

La Ley Orgánica del Supremo Tribunal de Justicia de la República Bolivariana de Venezuela en su artículo 21 señala que las acciones o recursos de nulidad contra los actos generales del poder público podrán intentarse en cualquier tiempo, pero los dirigidos a anular actos particulares de la administración caducarán en el término de seis meses, contados a partir de su publicación en el respectivo órgano oficial, o de su notificación al interesado.

\section{España}

Establece el artículo treinta y tres de la Ley Orgánica del Tribunal Constitucional que el recurso de inconstitucionalidad se formulará dentro del plazo de tres meses a partir de la publicación de la ley, disposición o acto con fuerza de ley.

\section{Comisión Interamericana de Derechos Humanos}

La Convención Americana sobre Derechos Humanos establece un plazo de seis meses para presentar ante la Comisión la petición o comunicación, 
contados a partir de la fecha en que el presunto lesionado en sus derechos haya sido notificado de la decisión definitiva (artículo 461 , inciso b). ${ }^{22}$

\section{Tribunal Europeo de Derechos Humanos}

El artículo 35 del Reglamento de Procedimientos de este Tribunal establece el plazo de seis meses para interponer la demanda, contados a partir de la fecha del dictado de la resolución interna definitiva.

Basten estos breves ejemplos para señalar los heterogéneos criterios respecto del plazo de interposición de la acción de inconstitucionalidad y medios de defensa de los derechos humanos. No existe una pacífica unificación; hay plazos que van de diez días (Chile) a intemporales (Bolivia). No obstante, no se observa en los textos legales o constitucionales que se realicen excepciones a los plazos procesales en el caso de violaciones graves a derechos humanos.

\section{COROLARIO}

En un Estado constitucional democrático debe privilegiarse la existencia de medios de control referidos a la defensa de los derechos humanos, estableciéndose tiempos procesales especiales para su ejercicio. En el caso de la acción de inconstitucionalidad, la inexistencia de un agravio real y concreto no debe desnaturalizar el verdadero contenido y alcance de las acciones tutelares de estos derechos, que, en todo caso, deben encaminarse a su protección.

Creemos que debe considerarse un tratamiento procesal especial a la acción de inconstitucionalidad en materia de defensa de los derechos hu-

22 Sin embargo, existen excepciones a este plazo, establecidas por el propio artículo 46:

"2. Las disposiciones de los incisos 1.a. y 1.b. del presente artículo no se aplicarán cuando:

a) no exista en la legislación interna del Estado de que se trata el debido proceso legal para la protección del derecho o derechos que se alega han sido violados;

b) no se haya permitido al presunto lesionado en sus derechos el acceso a los recursos de la jurisdicción interna, o haya sido impedido de agotarlos, y

c) haya retardo injustificado en la decisión sobre los mencionados recursos.

De lo anterior podemos desprender que en estos casos la petición puede interponerse en cualquier tiempo atendiendo al supremo interés de tutelar los derechos humanos violados o presuntamente violados". 
manos, toda vez que, atendiendo a su naturaleza de medio de control abstracto (no de defensa proveniente de un agravio directo), ${ }^{23}$ es posible lograr un efecto preventivo que evite la aplicación de una norma general (ley o tratado) lesiva a los derechos fundamentales, con las fatales consecuencias que esto representa.

Podrían otorgarse facultades constitucionales a la SCJN para que en los casos de graves violaciones a los derechos humanos derivados de normas generales el plazo de interposición de la acción de inconstitucionalidad fuera valorado por este alto tribunal, el cual analizaría la admisión del medio de control constitucional, o bien, prever un plazo, el cual, siguiendo a Kelsen, podría variar de tres a cinco años. ${ }^{24}$

\section{CONCLUSIONES}

Primera. No es posible hablar de una tutela judicial efectiva a los derechos humanos estableciendo breves plazos para impugnar una ley o tratado internacional posiblemente lesiva de los mismos.

Segunda. La característica de inatacable, mediante una acción de inconstitucionalidad, de una norma general (ley o tratado) violatoria de derechos humanos, por la omisión en el cumplimiento del plazo de interposición, colisiona de manera frontal con el principio pro homine.

Tercera. Es recomendable un nuevo análisis, por parte del poder reformador y del legislador secundario, respecto del plazo de interposición de la acción de inconstitucionalidad en los casos de violaciones a derechos humanos por parte de normas generales o tratados internacionales, considerando mayormente las recientes reformas a nuestra Constitución en el tema de los derechos fundamentales.

Cuarta. El otorgamiento de facultades constitucionales a la Suprema Corte de Justicia de la Nación, en el tema materia de este ensayo, aportaría un gran avance e indudablemente enriquecería los medios de defensa de los derechos humanos.

23 Como el juicio de amparo.

24 Lo que repugna a la razón jurídica es el hecho que una ley violatoria de derechos humanos continúe intemporalmente aplicándose, quedando fuera, por negligencia u omisión en el cumplimiento del plazo de interposición de la acción de inconstitucionalidad, su impugnación. 


\section{FUENTES CONSULTADAS}

Brage CAMAZANO, Joaquín, La acción abstracta de inconstitucionalidad, México, UNAM, 2000.

Cossío, José Ramón y Acha PÉrez, Luis M. de, La defensa de la Constitución, México, Distribuciones Fontamara, 2003.

FERRAJOLI, Luigi, Garantísmo, una discusión sobre derecho y democracia, Madrid, Trotta, 2006.

Herrera PÉrez, Alberto, "La dignidad humana en la Constitución federal mexicana", Revista de la Facultad de Derecho de México, México, t. LXVI, julio-diciembre de 2016.

HERRERA PÉREZ, Alberto, “Correlación jerárquica normativa de los tratados internacionales en materia de derechos humanos y la Constitución federal mexicana", Revista El Tribunal Superior de Justicia del Distrito Federal, núm. 22, año VIII, diciembre de 2015.

LÓPEZ-Ayllón, Sergio y VALladARES, Florencio, "Las acciones de inconstitucionalidad mexicana: balance empírico de doce años de ejercicio", Cuestiones Constitucionales, Revista Mexicana de Derecho Constitucional, México.

Soto Flores, Armando Guadalupe, La controversia constitucional y la acción de constitucionalidad como medios de control de la Constitución, México, UNAM, Instituto de Investigaciones Jurídicas, 2017.

Suprema CorTe De Justicia de la NACión, Grandes temas del constitucionalismo mexicano, la defensa de la Constitución, México, 2005.

Fecha de recepción: 17 de enero de 2017.

Fecha de aceptación: 19 de septiembre de 2018. 